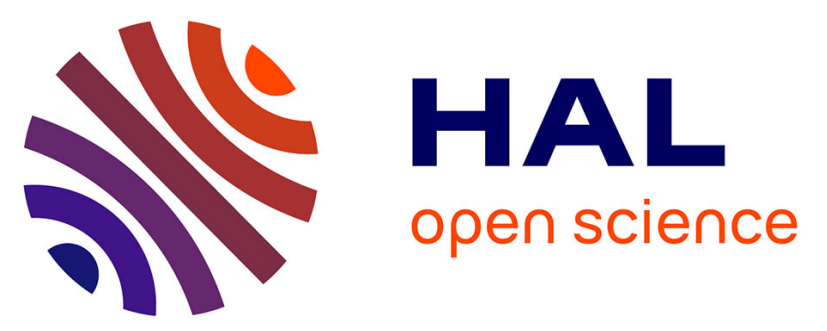

\title{
(20th ICPR) AN INNOVATIVE APPROACH FOR JOB PRE-ALLOCATION TO PARALLEL UNRELATED MACHINES IN THE CASE OF BATCH SEQUENCE-DEPENDENT MANUFACTURING ENVIRONMENT
}

Rita Gamberini, Francesco Lolli, Bianca Rimini, Matteo Torelli, Erica Castagnetti

\section{- To cite this version:}

Rita Gamberini, Francesco Lolli, Bianca Rimini, Matteo Torelli, Erica Castagnetti. (20th ICPR) AN INNOVATIVE APPROACH FOR JOB PRE-ALLOCATION TO PARALLEL UNRELATED MACHINES IN THE CASE OF BATCH SEQUENCE-DEPENDENT MANUFACTURING ENVIRONMENT. International Journal of Production Research, 2011, pp.1. 10.1080/00207543.2010.543296 . hal-00677868

\section{HAL Id: hal-00677868 https://hal.science/hal-00677868}

Submitted on 10 Mar 2012

HAL is a multi-disciplinary open access archive for the deposit and dissemination of scientific research documents, whether they are published or not. The documents may come from teaching and research institutions in France or abroad, or from public or private research centers.
L'archive ouverte pluridisciplinaire HAL, est destinée au dépôt et à la diffusion de documents scientifiques de niveau recherche, publiés ou non, émanant des établissements d'enseignement et de recherche français ou étrangers, des laboratoires publics ou privés. 


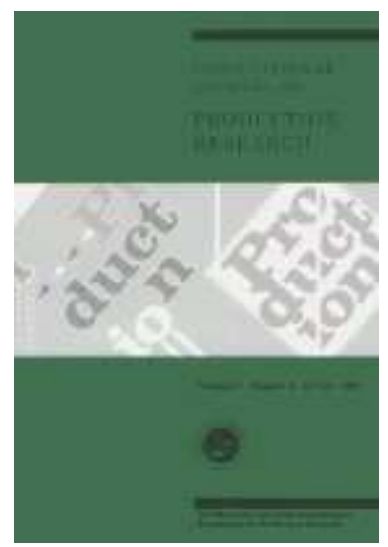

\section{(20th ICPR) AN INNOVATIVE APPROACH FOR JOB PRE- ALLOCATION TO PARALLEL UNRELATED MACHINES IN THE CASE OF BATCH SEQUENCE-DEPENDENT MANUFACTURING ENVIRONMENT}

\begin{tabular}{|r|l|}
\hline Journal: & International Journal of Production Research \\
\hline Manuscript ID: & TPRS-2010-IJPR-0460.R1 \\
\hline Manuscript Type: & Original Manuscript \\
\hline Author: & 12-Nov-2010 \\
\hline & $\begin{array}{l}\text { Complete List of Authors: } \\
\text { Engethods } \\
\text { Lelli, Francesco; University of Modena and Reggio Emilia, } \\
\text { Rimini, Bianca; University of Modena and Reggio Emilia, } \\
\text { Department of Engineering Sciences and Methods } \\
\text { Torelli, Matteo; Plannet S.r.I. } \\
\text { Castagnetti, Erica; University of Modena and Reggio Emilia, } \\
\text { Department of Engineering Sciences and Methods }\end{array}$ \\
\hline Keywords (user): & $\begin{array}{l}\text { Scheduling, parallel unrelated machines, setup sequence- } \\
\text { dependent, batch sizing }\end{array}$ \\
\hline Keywords: & BATCH SIZING, BATCH SCHEDULING \\
\hline
\end{tabular}

\section{SCHOLARONE \\ Manuscripts}




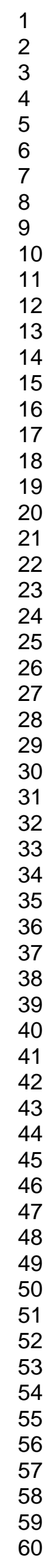

37 


\title{
AN INNOVATIVE APPROACH FOR JOB PRE-ALLOCATION TO PARALLEL UNRELATED MACHINES IN THE CASE OF A BATCH SEQUENCE-DEPENDENT MANUFACTURING ENVIRONMENT
}

\author{
R. Gamberini, F. Lolli, B. Rimini, M. Torelli ${ }^{\S}$, E. Castagnetti \\ Department of Engineering Sciences and Methods, University of Modena and Reggio Emilia \\ Via Amendola 2 - Padiglione Morselli, Reggio Emilia, Italy \\ $\S$ Plannet S.r.I., Viale Magenta 1/C, Reggio Emilia, Italy
}

\begin{abstract}
The problem of allocating jobs to a set of parallel unrelated machines in a make to stock manufacturing system is studied. The items are subdivided into families of similar products. Sequence-dependent setups arise when products belonging both to the same family and to different families are sequenced. Restrictions on the number of available setups should be considered. The availability of planning batch production exists. Nevertheless, batch size is not known a priori. Hence, a solving approach considering both a preassignment procedure and a scheduling algorithm is proposed. Specifically, the focus of the paper is on the pre-assignment methodology: a pre-assignment model (solved by a commercial solver) and two heuristics are presented and compared, in order to minimize the average idle residual capacity during the planning horizon, while considering pejorative factors related with the split volumes of the same product on different machines, unsatisfied demand along with demand produced in advance in each time period. The application to a case study is finally described in order to assess the performance of the proposed approach.
\end{abstract}

\section{Keywords:}

Scheduling, parallel unrelated machines, setup sequence-dependent, batch sizing. 


\section{INTRODUCTION}

Batch sizing and scheduling problems represent an important research area in the manufacturing field, due to the advantages related with the application of optimal principles, i.e. reduction of machine idle time as well as respect for due dates. On one hand, the optimal size of the production batches is studied, on the other hand, the operations sequence on each machine is analyzed. The combination of these problems proposed by several authors may be either hierarchical or simultaneous. In this paper, a hierarchical approach is addressed, since a solving framework breaking the problem down into two successive steps is proposed.

The first step looks at the pre-allocation of required items to the available resources, while respecting due dates and a subset of all the problem constraints, i.e. residual machine capacity. Furthermore, choices facilitating the definition of a good solution in the second step are preferred. Hence, a smoothing machine workload is addressed, along with limited fragmentation of the production of an item on different machines or different time buckets. The first aspect limits the occurrence of manufacturing postponement of items requiring a restricted subset of machines, which may be saturated while others are idle. The latter aspect aims to limit the requirement of setups. Moreover, the habit of anticipating the production of items required in the future is also limited in order to avoid excessive requirements of storage space and resources.

The second step of the solving approach aims to generate the sequences of manufactured batches (suggested by the preallocation step) on the available production resources, while respecting a wide set of operative constraints, i.e. the availability of on-line operators, machine equipment, operators for setups, along with limits on the maximum number of possible setups or on the batch dimension.

In particular, this paper focuses on the first step achieving a mathematical model (subsequently solved by means of a commercial solver) and two heuristics, which are compared in a multi-criteria logic. After the introduction of the main results presented in literature (section 2), the notation adopted (section 3), the definition of the specifics of the production system analyzed (section 4) and the problem statement (section 5) is introduced. Then the solving framework is described (section 6). The proposed heuristics are presented in sections 7 and 8 and compared in section 10. Section 9 describes the guidelines of the sequencing algorithm coupled with the pre-assignment procedures studied in order to describe the whole solving environment better to the reader. Some conclusions are drawn in section 11.

\section{LITERATURE REVIEW}

The interest in the scheduling problem considering setup began in the mid-1960s and published results are summarized in the survey papers of Liaee and Emmons (1997), Yang and Liao (1998), Cheng et al. (2000), Allahverdi et al. (1999, 2000), Potts and Kovalyov (2000). Furthermore, if scheduling is coupled with the problem of defining optimal batches, the survey papers of Salomon et al. (1991), Drexls and Kimms (1997), Karimi et al. (2003) can be seen.

Different shop environments are studied: single machine, parallel machines, flow shop, job shop. Both sequence independent and sequence-dependent setups are analyzed, along with the batch and non-batch planning environment.

In accordance with the objective of the paper, this section will focus on parallel machines and specifically on solving approaches for problems involving unrelated production resources with a sequence-dependent setup operating in a batch planning environment. The main contributions are described in the sequel and summarized in table 1.

Two main subgroups can be identified, those considering pre-defined batch dimensions (usually in accordance with the amount of customers orders) and those considering an unknown batch size a priori (subsequently calculated in accordance with customer order estimation along with the need to minimize storage, setup, production, stockout and backlog costs, or a combination of them). As concerns the first subgroup, the main recent contributions are cited in the sequel. Jeong et al. (2001) develop a scheduling system for the Thin Film Transistor Liquid Crystal Display assembly process. Kim et al. (2002) propose a Simulated Annealing (SA) approach minimizing tardiness. Kim et al. (2003) minimize the total weighted tardiness and test four heuristics, including the earliest weighted due date rule, the shortest weighted processing time, the two-level heuristic and the SA method. Finally, in the Kim et al. (2006) version, the metaheuristic techniques published in Kim et al. $(2002,2003)$ are improved again. Arnaout et al. (2006) study the stochastic version of the problem, where processing and sequence-dependent setup times are stochastic. Nevertheless, in the aforementioned contributions, constraints concerning operators and equipment needed during production and setup are disregarded, even if they often characterize real-life problems (Gamberini et al. 2005). Only Celano et al. (2008) consider the problem of scheduling both the machine production 


\section{NOTATION}

$i=1, \ldots, n \quad$ switch items to be allocated

$j=1, \ldots, m \quad$ available production machines

$t=1, \ldots T \quad$ time periods in the planning horizon

$d_{i t} \quad$ demand (forecasted and/or confirmed) of switch item $i$ in time period $t$

$\operatorname{ACap}_{j t} \quad$ available capacity of machine $j$ in time period $t$

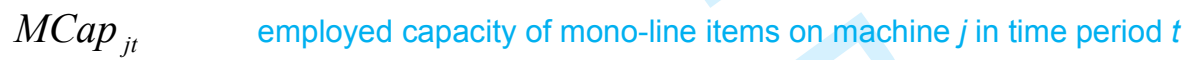

$\overline{M C a p}_{j t} \quad$ unsatisfied capacity request of mono-line items on machine $j$ in time period $t-1$

$p_{i j} \quad$ productivity of machine $j$ when manufacturing switch item $i$

a split penalty because of splitting total volume of the same item on different machines

b unsatisfied demand penalty

$c \quad$ early penalty linked to demand percentage allocated earlier than the request date

$z_{i j}= \begin{cases}1, & \text { if item } i \text { may be produced by machine } j \\ 0, & \text { otherwise }\end{cases}$

Decision variables

$x_{i j t}= \begin{cases}1, & \text { if item } i \text { is allocated to machine } j \text { in time period } t \\ 0 & \text { otherwise }\end{cases}$

$y_{i j t} \quad$ demand percentage of switch item $i$ allocated to machine $j$ in time period $t$

$v_{i j t} \quad$ demand percentage of switch item $i$ allocated in advance to machine $j$ in time period $t$

\section{THE ANALYZED OPERATIVE ENVIRONMENT}

In the sequel, the operative environment analyzed in this paper is described, in order to underline the characteristics that are fitting and unfitting with production systems studied in published papers.

Unrelated machines constitute the system. The production cycles of the manufactured items can be executed only on a subset of the available resources. In particular, mono-line items can only be processed by one specific machine while switch items can be allocated to a subset of the machines containing more than one element. Furthermore, each machine requires a pre-specified operator team for assuring its correct operation. Finally, pre-defined manufacturing equipment is requested. Hence the production of each item is strictly related to its availability.

A sequence-dependent setup structure is considered. Each item (named in the sequel Stock Keeping Unit - SKU) belongs to a subfamily (named in the sequel Intermedium), in accordance with pre-specified common characteristics of the manufacturing cycle. Analogously, subfamilies with common features are grouped into a family (named in the sequel Size). Sequence-dependent setups occur when the manufactured item changes, even if products belonging to the same subfamily/family are chosen. Hence, setup may occur between different SKUs of the same Intermedium and Size (named in 
the sequel SKU change), between different SKUs belonging to different Intermediums, however belonging to the same Size (named in the sequel Intermedium change) or finally between different SKUs belonging to a different Intermedium and a different Size (named in the sequel Size change).

Furthermore, each setup requires a pre-specified operator team for its correct execution. Finally, due to union agreements signed between the analyzed company and the operators, only a predefined number of setups can be managed both each day and each week.

A make to stock operative environment is studied. Hence, production planning has a degree of freedom in the definition of batch size, not strictly related with customer orders.

Nevertheless, the analyzed company operates in the hygiene products field (e.g. diapers, paper towels, etc...). Hence a voluminous product, with a low unit cost is managed. On one hand, the standardization of the market field addresses the minimization of the risk of stock out, in order to prevent the risk of losing sales. Thus, production batches with numerous items are suggested. On the other hand, the high incidence of the unit storage cost addresses the minimization of the available stocks (and consequently the limitation of the dimensions of the production batch size). Consequently, in the definition of the production batches, a trade-off between opposite requirements is considered. Furthermore, minimum batch dimensions, defined by the company manager, in accordance with previous analyses, need to be satisfied.

Moreover, the unit storage and stock out costs are uncertain. The unit storage costs are calculated using the ratio between the total storage cost (strictly related with, e.g., available storage resources, operators and forklifts involved, as well as operative costs such as those due to illumination, heating/air conditioning ...) and the mean stored quantity of products. Nevertheless, the mean stock amount depends on the production batch policy, that is the required output. Hence, only an evaluation of past unit storage costs is available. Likewise, stock out costs are related with uncertain data, such as lost sales. As a consequence, an approach disregarding the definition of unit storage and stock-out costs is implemented in this version of the work. Rather, considerations concerning the amount of demand satisfied in advance and consequently addressed to storage areas and unsatisfied requested items are made. However, in a further development of the work, economical considerations including the analysis of storage costs (even affected by past data and strategies) and stockout costs (even affected by uncertainties) may be inserted.

Similarly as underlined in Kim et al. (2003), due to the difficulty of the analyzed operative environment, it is an acceptable practice to find an appropriate heuristic solution approach rather than an optimal solution methodology.

A solution approach hierarchically proposing an allocation of jobs to the available resources in each time horizon, by only considering a subset of the problem constraints (pre-allocation procedure) and subsequently a scheduling algorithm defining the final batch sequence on the machines, in accordance with the full set of problem constraints, is implemented in this paper.

In the following section, the problem statement addressing the solution of the pre-allocation step is described.

\section{THE PROBLEM STATEMENT}

Following the suggestions reported in Pinto and Grossman (1998) and in Monkman et al. (2008), this paper focuses on the pre-allocation procedure.

A problem statement is reported in the sequel, by means of a mathematical model.

Before introducing this, note that the planning horizon is divided into time buckets of known length, considering the trade-off between the delay risks (related with too long buckets) and the disadvantages due to excessive fractioning in the horizon of production volumes (related with too small buckets). Moreover, $d_{i t}$ is pre-defined for each time bucket in accordance with the delivery dates. Finally, observe that the available production capacity for switch items is fixed. Thus, in each time period and on each production machine, the available capacity for switch items is obtained from the total capacity minus the capacity for mono-line items. If the capacity request for a mono-line item in a specific time period exceeds the total capacity of the machine, then the unsatisfied amount will be attributed to the successive time period.

In the proposed model the objective function is as follows:

$$
\min Q=\sum_{t=1}^{T}\left(\frac{\sum_{j=1}^{m} R C_{j t} \%}{m}+a \sigma_{t}+b \mu_{t}+c \lambda_{t}\right)
$$

Subject to:

$\sigma_{t}=\frac{\sum_{i=1}^{n} \sum_{j=1}^{m} x_{i j t}}{n}$

$d b_{i t}=d_{i t}+u_{i, t-1}$

$u_{i t}=d b_{i t} \times\left(1-\sum_{j=1}^{m} y_{i j t}-\sum_{j=1}^{m} v_{i j, t-1}\right) \quad \forall i, t$

$$
\begin{aligned}
& u_{i t}=d b_{i t} \times\left(1-\sum_{j=1} y_{i j t}-\sum_{j=1} v_{i j, t-1}\right) \quad \forall i, t \\
& \operatorname{SCap}_{j t}=A \operatorname{Cap}_{j t}-\operatorname{MCap}_{j t}-\bar{M} \operatorname{Cap}_{j t} \forall i, t
\end{aligned}
$$


The objective function (Eq.(1)) aims to minimize the total average residual capacities of the $m$ production machines, keeping count of three appropriately weighted pejorative factors:

- $\quad$ the split volumes on the machines in each time period (with weight $a$ );

- $\quad$ unsatisfied demand in each time period (with weight $b$ );

- $\quad$ demand produced in advance (with weight $c$ ).

Constraints (2) to (9) bound the values introduced in the objective function. Eq.(2) defines the average number of fractioning for each switch item in time period $t$. Eq.(3) evaluates the amount of demand of each switch item $i$ to be allocated in time period $t\left(d b_{j t}\right)$, obtained by the sum of the portion of demand allocated to time period $t\left(d_{j t}\right)$ and the portion of demand not satisfied in period $t-1\left(\mathrm{u}_{j, t-1}\right)$. Eq. (4) defines the unsatisfied demand for the switch item $i$ in time period $t$. Eq.(5) represents the available capacity of the machine $j$ in time period $t$ for allocating switch items, from which the remaining capacity is achieved, both in its absolute (Eq.(6)) and percentage (Eq.(7)) value. Eq.(8) defines the average percentage of unsatisfied demand in time period $t$ while Eq.(9) is the average volume of switch items requested in time period $t+1$ that are allocated to time period $t$ (in advance). Eq.(10) is the combination of two distinct constraints; the first guarantees that each switch item is allocated to machines available for it, while the second establishes that the percentage of allocated demand of the same item is positive only for the chosen machines. Eq.(11) has the same significance as Eq.(10) but only refers to demand allocated in advance with respect to the current time period $t$. Eq.(12) imposes respect for the available capacity of each production machine $j$ in time period $t$, therefore the remaining capacity has a non-negative value. Eq.(13) guarantees that the total allocated volume of each item to the machines does not exceed the total requested volume in each time period $t$. Eq.(14) and Eq.(15) allow variables $u_{i 0}$ and $v_{i j o}$ to be initialized, while Eq.(16), Eq.(17) and Eq.(18) define the dominium of the decision variables.

\section{THE SOLVING FRAMEWORK}

The adopted solving framework is depicted in figure 1.

A pre-allocation approach, able to allocate jobs to available machines in accordance with due-dates and capacity constraints is coupled with a scheduling algorithm considering the full complexity of the problem by starting with job allocations proposed in the previous step.

The inputs of the pre-allocation procedure are represented by demand forecasts and confirmed customer orders in future periods, the productivity of each available machine and feasibility constraints. The outputs are constituted by production volumes allocated to each machine. 
A dispatching algorithm solving a sequencing problem is applied to the obtained results. Further inputs are constituted by system start up conditions along with data concerning the accepted maximum number of setups, the work-teams calendar, the setups-team calendar and the minimum accepted batch dimension.

Obviously, in order to assure coherence between the first item assignment achieved by the pre-allocation algorithm and the final solution, the adoption of the same time bucket length, the same resource availability constraints and the same feasibility constraints is guaranteed.

\section{[TAKE IN FIGURE 1]}

Specifically, for the pre-assignment steps, three alternatives are studied: the adoption of a commercial solver for the solution of the model described in section 5 and the definition of two heuristics (named $\mathrm{H} 1$ and $\mathrm{H} 2$ ), described in sections 7 and 8 , respectively.

\section{HEURISTIC H1}

The first heuristic proposed aims, like the solution of the assignment model presented in section 5 , to pre-allocate the production volumes to the machines in each time period. The objectives that the heuristic follows are both balancing the work-load of the machines and keeping the integrity of switch items in order to minimize the total setup number. Therefore, $\mathrm{H} 1$ applies a four-step procedure, introduced in the sequel step by step.

A summarizing scheme is proposed in figure 2.

\section{[TAKE IN FIGURE 2]}

\subsection{Mono-line item allocation}

Since mono-line items can only be processed by a specific machine, the heuristic starts with their allocation. Therefore, the available capacity of the machines for switch items is influenced by the mono-line item allocation, which does not represent a decision step but a constraint. Note that starting from the allocation of mono-line items is justified by the fact that, if the heuristic starts from the switch items, then the risk of stock-out for mono-line item occurs.

\subsection{Switch item allocation}

For defining a criterion for switch item allocation, several new parameters must be introduced, in accordance with scheduling guidelines reported in Chuang et al. (2009) and in Hu et al. (2010).

Let be:

$U_{i}=$ cluster of machines which can process item $i$;

$C R_{j}=$ saturation coefficient of machine $j[\%] ;$

$\operatorname{Pr} i U t i l_{j}=$ ranking given to production machine $j$ based on its utilization cost;

$W=$ pejorative factor for $C R_{j}$ linked to the utilization of machine $j$ with a specified $\operatorname{Pr} i U t i l_{j}$ value.

The criterion applied in order to allocate switch item $i$ to Imachine $j$ is the following: $\min _{j \in U_{i}}\left(C R_{j}+\operatorname{Pr} i U t i l_{j} \cdot W\right)$

Note that the correction of the saturation coefficient guarantees the possibility to customize the heuristic according to discretionary criteria.

\subsection{Reallocation of small volumes}

In order to reduce the excessive splitting of production volumes and then the setup number, the minimum lot-size $Q \min _{i}$ is introduced to evaluate the convenience of a setup rather than allocating the switch item on an alternative available machine. In fact, after step 2, too much splitting may be achieved. Hence, switch items are reallocated in order to satisfy the minimum requested batch sizes. Specifically, in order to simplify the satisfaction of this constraint, a corrective factor $R$, belonging to the range $[0,1]$ can be introduced, as a multiplier of $Q_{\min }$.

\subsection{Reordering of volumes}

Since the heuristic first allocates the mono-line items and then the switch items, a last step aimed at checking the deadlines is necessary in order to avoid violating the delivery dates. Thus, all items are reordered based on their priorities.

\section{HEURISTIC H2}

The other heuristic proposed moves from the same aprioristic steps, which are the definition of the scheduling horizon and then the determination of time bucket length, available capacities of the machines in each time bucket and requested volumes of each item in each time bucket. As well as $\mathrm{H} 1, \mathrm{H} 2$ may be analyzed step by step. Its structure is depicted in figure 3. 
[TAKE IN FIGURE 3]

\subsection{Allocation of mono-line items}

$\mathrm{H} 2$ starts from mono-line item allocation. If the available capacities of the machines are not sufficient to satisfy the requested demand of mono-line items, then the heuristic $\mathrm{H} 2$ tries to anticipate it in the previous time bucket.

\subsection{List switch items in descending order of volume and machines in increasing order of saturation coefficient}

In preparation for the following steps, switch items are listed giving higher priority to those with bigger volumes. Moreover, the machine selection criterion depends on the saturation mark, therefore higher priority will be given to less saturated machines.

\subsection{Allocation of switch items}

Reducing the splitting of the volumes on the machines is the main objective of this step. Two sub-steps are introduced. The first guarantees, as far as possible, the allocation of whole volumes to the machines, without the splitting recurring, while the second achieves the re-allocation of volumes when the first is not able to allocate each switch item to a single machine. Starting from the first time period, switch items with the bigger volumes are allocated to the least saturated machine, in accordance with the order achieved in the previous step. Each item is only allocated to a machine if its requested capacity is less than or equal to the residual capacity. In the event of negative response, the item joins a queue before being fractioned by the second sub-step.

\subsection{Producing switch items in advance}

Unsatisfied demand has to be allocated, thus it is anticipated in the previous time bucket, in accordance with scheduling guidelines reported in Chang et al. (2008). In case of unavailable capacity, the remaining volumes are split between the available machines.

Therefore $\mathrm{H} 2$ prefers advance production (and consequently stock creation) rather than risking a stock-out.

\section{SEQUENCING ALGORITHM}

Figure 4 shows the scheme of the sequencing algorithm applied to the results of the pre-allocation procedure.

The objective function (OF) addressing the choices is the weighted sum of the deviations between the obtained completion dates and pre-defined objective dates.

After the determination of time bucket length in accordance with the pre-allocation heuristic applied (STEP 1), the priority level of each machine is explored in order to define the sequencing order (STEP 2). The ordering criteria are influenced by the number of Sizes produced by each machine and its saturation coefficient. Thus, the guideline is to start from the most critical resource. After loading the input data concerning the machines (STEP 3) and the start up conditions, e.g. which SKU (item) is in progress (STEP 4), a macro step (STEP 5) analyses each available change of Size. Thus, the sequences both of Intermediums that compose the Size and of SKUs that compose each Intermedium are achieved. In order to determine the successive available change of Size (STEP 5.1), as well as the successive available change of Intermedium into the analysed Size (STEP 5.3), several conditions are evaluated. In particular, a change either of Size or Intermedium can be made in accordance with three necessary conditions, e.g. the maximum number of available setups (per day/per week), the availability of setup operators and the achievement of the minimum batch size. Moreover, in order to maintain a high customization mark, two parameters (FSC and FIC), are considered and selected by the user, in accordance with the required production flexibility or the accepted stock-out risk. Detailed lot-sizing of each SKU and of each Intermedium is achieved for the simulated Size in STEP 5.2, after considering the available production time, along with the minimum batch size constraints.

Thus, for each Intermedium in the current Size, SKUs are sequenced (STEP 5.3.1) and then, after each Intermedium has been simulated, the permutation of Intermediums is carried out in order to minimize the objective function (STEP 5.4). STEP 6 replicates the permutation of the Sizes after each of them has been simulated, still with respect to the minimization of the objective function, while STEP 7 passes onto the next machine in the time bucket with respect to the pre-assigned order. At the end of the machine scheduling in the first bucket and before passing onto the next bucket (STEP 9), the algorithm redetermines the priority levels of the machines in order to achieve the sequencing order for the next time bucket (STEP 8). At the very end of the planning horizon, the average objective function on the machines in the module is evaluated (STEP 10) for estimating a good indication of the sequencing algorithm.

\section{[TAKE IN FIGURE 4]}

\section{CASE STUDY}

A case study describing the behavior of the proposed mathematical model and the two heuristics is presented. Furthermore some considerations about their performance are made.

More in-depth experimentation is not the aim of this paper, even if fine tuning of the solving approach requires this. It will be the main topic of a further work, where the conjuncted execution of the pre-assignment approach and scheduling algorithm will also be described, both in an experimental data set and in a real life case study.

Collected data on the scenario analyzed in this case study are summarized in the following tables. In particular, three time buckets are evaluated. Both mono-line items and switch items are considered in the experimental environment. 
Nevertheless, only data concerning switch item volumes $d_{i t}$ to be produced in such time horizons (for $\left.t=1, \ldots, 3\right)$ are reported in table 2. In fact, the allocation of mono-line items represents the aprioristic step both for the mathematical model and for the two heuristics. Therefore, the initial situation with the lines partially occupied by the mono-line items is a constraint of the problem. In figure 5, mono-line items and switch item machines are plotted and indicated in the abscissa axis respectively by $8,4, \mathrm{H}$ and $8,13,14,18$. Given the focus of the paper on the pre-allocation of switch items, below only machines devoted to their manufacturing $(8,13,14,18)$ will be studied again, nevertheless in figure 5 in each time bucket (indexed by values 1,2 , 3 ) the initial situation of each machine is depicted.

The productivity $p_{i j}$ of each switch item machine and its available capacity $A C a p_{i t}$ in each time bucket are reported in tables 3 and 4 respectively. In the sequel, the unit MSU is used instead of SKU for simplicity (1 MSU $=240000 \mathrm{SKU})$.

\section{[TAKE IN TABLES 2, 3, 4]}

\section{[TAKE IN FIGURE 5]}

The saturation coefficients of switch item machines are reported in table 5.

\section{[TAKE IN TABLE 5]}

In order to compare the mathematical model solved with the two heuristics, four performance indicators are evaluated: Average number of split volumes (ANSV) = average number of fractioning per switch item in each time period, calculated as described in equation (20):

$$
A N S V=\frac{N F}{18}
$$

where $N F$ indicates the sum of the number of machines manufacturing each item in each time period and the denominator is obtained by multiplying the number of items (6) and the number of time buckets (3). When each item is allocated to one machine per time bucket, ANSV assumes the value 1. Otherwise an increasing value is recorded;

Average unsatisfied switch demand $(A \cup S D)=$ average percentage of unsatisfied switch demand with respect to the total switch demand request in the scheduling horizon. Given the switch item volumes to be allocated in each time bucket (132.26, 132.55 and 167.59 SKU respectively, see table 2), the average unsatisfied switch demand is calculated as described in equation (21):

$$
A U S D=\frac{\frac{u n 1}{132.26}+\frac{u n 2}{132.55}+\frac{u n 3}{167.59}}{3} \times 100
$$

where un1, un2 and un 3 are the number of unsatisfied switch items in time buckets 1, 2 and 3 respectively; Average early switch demand $(A E S D)=$ average percentage of switch demand produced in advance. Given the switch item volumes to be allocated, such an indicator is evaluated as described in equation (22):

$$
A E S D=\frac{\frac{e a_{1,4341}}{15.53}+\frac{e a_{2,4341}}{20.14}+\ldots+\frac{e a_{1,7016}}{13.61}+\frac{e a_{2,7016}}{22.74}}{12} \times 100
$$

where $e a_{t, i}$ represents the volume of switch item $i$ that is allocated to one time bucket back $(t)$ from the target time bucket $(t+1)$. The denominator is obtained by multiplying the number of items (6) and the number of analyzed time buckets ( $t=1$ and $t=2$ ). Obviously, time bucket $t=3$ is disregarded since it should contain anticipated orders from time bucket $t=4$, whose values are not recorded in the case study;

Average switch filling rate $(A S F R)=$ average saturation coefficient of the switch item machines in each time period, calculated as described in equation (23):

$$
A S F R=\frac{R C_{8,1}+R C_{13,1}+\ldots+R C_{14,3}+R C_{18,3}}{12} \times 100
$$

where $R C_{j, t}$ is the saturation coefficient of the switch item machine $\mathrm{j}$ in time bucket $\mathrm{t}$. The denominator is obtained by multiplying the number of machines manufacturing switch items (4) and the number of analyzed periods (3). In the sequel the behavior of the two heuristics is described and compared with the mathematical model solved.

\subsection{Mathematical model}

As underlined in section 6, the objective function (Eq.(1)) aims to minimize the total average residual capacities of the $m$ production machines, considering three pejorative factors $\left(\sigma_{t}, \mu_{t}, \lambda_{t}\right)$ appropriately weighted $(a, b, c)$. In accordance with the guidelines proposed by the management, since the demand satisfaction in each time period has top priority, then the highest value is given to weight $b$. In particular, in the present case study $a, b$ and $c$ are equal to $1 \%, 98 \%$ and $1 \%$ respectively. In order to achieve a solution, the mathematical model is implemented on a commercial solver. Given its heuristic nature, two alternative solutions (named S1 and S2) are presented, in order to better evaluate its behavior in the solution space. Specifically, the volume pre-allocations achieved by the mathematical model are plotted in figures 6 and 7 and then explained in tables 6 and 7. 


\subsection{Heuristic $\mathrm{H} 1$}

Heuristic $\mathrm{H} 1$ firstly selects the switch items to be allocated randomly and then assigns them to the switch item machines. The list of such machines is in ascending order of a certain parameter, that is the sum of the saturation coefficient and a ranking based on the utilization cost of each machine (with weight $W$ ). In the present case study, the utilization cost of each machine is supposed to be directly proportional to its productivity (see table 3 ), with weight equal to 0.01 . For example, item 4341 is firstly selected in time bucket 1 and then assigned to machine 8 because $(0.08+0.1133)<(0.14+0.0972)$ and so on .

The volume pre-allocation achieved by heuristic $\mathrm{H} 1$ is plotted in figure 8 and then explained in table 8 , where gray cells refer to uncompleted orders in the available time.

[TAKE IN FIGURE 8, TAKE IN TABLE 8]

\subsection{Heuristic $\mathrm{H} 2$}

Heuristic $\mathrm{H} 2$ starts by giving higher priority to switch items with bigger volumes. Moreover, the criterion of selecting a machine depends on the saturation mark, therefore higher priority will be given to less saturated machines. The ordered lists of switch items and switch item machines are presented in tables 9 and 10 respectively.

\section{[TAKE IN TABLES 9 AND 10]}

The volume pre-allocation achieved by heuristic $\mathrm{H} 2$ is plotted in figure 9 and then explained in table 11 , where gray cells refer to uncompleted orders in the available time.

\section{[TAKE IN FIGURE 9, TAKE IN TABLE 11]}

\subsection{Results}

The experimental results are summarized in table 12.

Note that the average unsatisfied switch demand achieved by the two solutions of the mathematical model is null because of the higher priority given to the demand satisfaction in the objective function. Otherwise, the mathematical model penalizes the average early switch demand $(10.0 \%$ in $\mathrm{S} 1$ and $10.2 \%$ in S2). The heuristic $\mathrm{H} 1$ gives the best performance in terms of the average early switch demand, that is null because it does not work towards the recuperation of capacity through the time periods, unlike the mathematical model and the heuristic $\mathrm{H} 2$, which obtained comparable results. However, the average switch filling rate obtained by the mathematical model is higher $(96.7 \%$ in $\mathrm{S} 2)$ than those obtained by heuristics $\mathrm{H} 1$ and $\mathrm{H} 2$ (92.1\% and $95.3 \%$ respectively).

\section{[TAKE IN TABLE 12]}

\section{CONCLUSIONS}

The problem of joint batch sizing and sequencing jobs on production resources in complex real-life scenarios is a problem requiring much more attention in literature, due to advantages related with their optimal implementation. Hence, in this paper, an innovative approach is proposed, considering unrelated machines, sequence-dependent setups, batch production environments and constraints on the availability of work-teams, setup-teams and the maximum number of available setups. The adopted guideline is the separation of the volume pre-allocation from the sequencing algorithm and then their hierarchical integration. In particular, this paper focuses on presenting and comparing three different volume pre-allocation methods, i.e. a mathematical model, subsequently solved, and two heuristics. In the analyzed case study interesting performances of the mathematical model and $\mathrm{H} 2$ emerge. 


\begin{tabular}{|c|c|c|c|c|c|c|c|c|c|}
\hline \multirow[b]{2}{*}{ Authors } & \multirow[b]{2}{*}{ Year } & \multirow[b]{2}{*}{$\begin{array}{l}\text { Objective } \\
\text { function }\end{array}$} & \multirow[b]{2}{*}{ Batch } & \multirow{2}{*}{$\begin{array}{l}\text { Certain } \\
\text { storage } \\
\text { and } \\
\text { stockout } \\
\text { costs }\end{array}$} & \multicolumn{5}{|c|}{ Constraints } \\
\hline & & & & & $\begin{array}{l}\text { On-line } \\
\text { operators }\end{array}$ & $\begin{array}{l}\text { Machine } \\
\text { equipment }\end{array}$ & $\begin{array}{l}\text { Setup } \\
\text { operators }\end{array}$ & $\begin{array}{l}\text { Maximum } \\
\text { number of } \\
\text { setup }\end{array}$ & $\begin{array}{l}\text { Minimum } \\
\text { batch size }\end{array}$ \\
\hline Kang et al. & 1999 & (1) & $\mathrm{U}$ & $\mathrm{Y}$ & $\mathrm{N}$ & $\mathrm{N}$ & $\mathrm{N}$ & $\mathrm{N}$ & $\mathrm{Y}$ \\
\hline Clark and Clark & 2000 & (2) & $\mathrm{U}$ & $\mathrm{Y}$ & $\mathrm{N}$ & $\mathrm{N}$ & $\mathrm{N}$ & $\bar{Y}$ & $\mathrm{~N}$ \\
\hline Akkiraju et al. & 2001 & (3) & $\mathrm{U}$ & $\mathrm{Y}$ & $\mathrm{N}$ & $\mathrm{N}$ & $\mathrm{N}$ & $\mathrm{N}$ & $\bar{Y}$ \\
\hline Jeong et al. & 2001 & (4) & $\mathrm{D}$ & $\mathrm{N}$ & $\mathrm{N}$ & $\mathrm{N}$ & $\mathrm{N}$ & $\mathrm{N}$ & $\mathrm{N}$ \\
\hline Kim et al. & 2002 & (5) & $\mathrm{D}$ & $\mathrm{N}$ & $\mathrm{N}$ & $\mathrm{N}$ & $\mathrm{N}$ & $\mathrm{N}$ & $\mathrm{N}$ \\
\hline Meyr & 2002 & (6) & $U$ & $\mathrm{Y}$ & $\mathrm{N}$ & $\mathrm{N}$ & $\mathrm{N}$ & $\mathrm{N}$ & $\bar{Y}$ \\
\hline Kim et al. & 2003 & (7) & $\mathrm{D}$ & $\mathrm{N}$ & $\mathrm{N}$ & $\mathrm{N}$ & $\mathrm{N}$ & $\mathrm{N}$ & $\mathrm{N}$ \\
\hline Arnaout et al. & 2006 & (8) & $\mathrm{D}$ & $\mathrm{N}$ & $\mathrm{N}$ & $\mathrm{N}$ & $\mathrm{N}$ & $\mathrm{N}$ & $\mathrm{N}$ \\
\hline $\begin{array}{c}\text { Fandel and } \\
\text { Stammen-Hegene }\end{array}$ & 2006 & (9) & $U$ & $\mathrm{Y}$ & $\mathrm{N}$ & $\mathrm{N}$ & $\mathrm{N}$ & Y & $\mathrm{N}$ \\
\hline Kim et al. & 2006 & $(7)$ & $D$ & $\mathrm{~N}$ & $\mathrm{~N}$ & $\mathrm{~N}$ & $\mathrm{~N}$ & $\mathrm{~N}$ & $\mathrm{~N}$ \\
\hline \multirow[t]{3}{*}{ Celano et al. } & 2008 & (5), (10) & $\mathrm{D}$ & $\mathrm{N}$ & $\mathrm{N}$ & $\mathrm{N}$ & $\mathrm{Y}$ & $\mathrm{N}$ & $\mathrm{N}$ \\
\hline & & \multirow[b]{2}{*}{$\begin{array}{l}\text { Objective } \\
\text { function }\end{array}$} & \multirow[b]{2}{*}{ Batch } & \multirow{2}{*}{$\begin{array}{l}\text { Certain } \\
\text { storage } \\
\text { and } \\
\text { stockout } \\
\text { costs }\end{array}$} & \multicolumn{5}{|c|}{ Constraints } \\
\hline & & & & & $\begin{array}{l}\text { On-line } \\
\text { operators }\end{array}$ & $\begin{array}{l}\text { Machine } \\
\text { equipment }\end{array}$ & $\begin{array}{l}\text { Setup } \\
\text { operators }\end{array}$ & $\begin{array}{l}\text { Maximum } \\
\text { number of } \\
\text { setup }\end{array}$ & $\begin{array}{l}\text { Minimum } \\
\text { batch size }\end{array}$ \\
\hline \multirow{3}{*}{\multicolumn{2}{|c|}{$\begin{array}{l}\text { Operative environment in the } \\
\text { case study }\end{array}$}} & & $U$ & $\mathrm{~N}$ & $\mathrm{Y}$ & $\mathrm{Y}$ & $\mathrm{Y}$ & $\mathrm{Y}$ & $Y$ \\
\hline & & & & Certain & \multicolumn{5}{|c|}{ Constraints } \\
\hline & & $\begin{array}{l}\text { Objective } \\
\text { function }\end{array}$ & Batch & $\begin{array}{l}\text { storage } \\
\text { and } \\
\text { stockout } \\
\text { costs }\end{array}$ & $\begin{array}{l}\text { On-line } \\
\text { operators }\end{array}$ & $\begin{array}{l}\text { Machine } \\
\text { equipment }\end{array}$ & $\begin{array}{l}\text { Setup } \\
\text { operators }\end{array}$ & $\begin{array}{l}\text { Maximum } \\
\text { number of } \\
\text { setup }\end{array}$ & $\begin{array}{l}\text { Minimum } \\
\text { batch size }\end{array}$ \\
\hline \multicolumn{10}{|l|}{ Proposed approach: } \\
\hline \multicolumn{2}{|l|}{$\begin{array}{l}\text { Pre-assignment } \\
\text { procedure }\end{array}$} & & $U$ & $\mathrm{~N}$ & 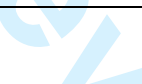 & & & & \\
\hline \multicolumn{2}{|c|}{ Scheduling algorithm } & & & & $\mathrm{Y}$ & $\mathrm{Y}$ & $\mathrm{Y}$ & $\mathrm{Y}$ & $\mathrm{Y}$ \\
\hline
\end{tabular}

(1) To minimize inventory holding costs, sequence-dependent setup costs and production costs minus sales revenue

(2) To minimize holding and backlog penalty costs

(3) Multiple objectives: To minimize tardiness, earliness, setup cost and time, inventory cost, job-machine assignment cost, batch size violations and downstream bottlenecks and inefficiencies.

(4) To minimize the mean flow time of each manufactured batch and deviation from the production demand

(5) To minimize tardiness

(6) To minimize inventory holding costs, sequence-dependent setup costs and line specific production costs

(7) To minimize weighted tardiness

(8) To minimize weighted mean completion time

(9) To minimize inventory holding costs, sequence-dependent setup costs, production costs and the cost of maintaining the machines' setup conditions in the planning horizon.

(10) Multiple secondary objectives: To minimize makespan, the cell blocking time, the cell waiting time. To maximize the worker operating time.

$\mathrm{D}=$ defined a priori (i.e. in accordance with customers orders)

$\mathrm{U}=$ undefined a priori (hence requiring a definition)

$\mathrm{Y}=$ yes

$\mathrm{N}=\mathrm{No}$

Table 1: Main literature contribution in the field of scheduling problems for unrelated parallel machines. 


\begin{tabular}{|c|c|c|c|c|}
\hline & Machines & Bucket 1 & Bucket 2 & Bucket 3 \\
\hline 4341 & 8,13 & 7.07 & 15.53 & 20.14 \\
\hline 7001 & 8,13 & 32.23 & 28.45 & 37.67 \\
\hline 7018 & 14,18 & 16.60 & 19.72 & 18.45 \\
\hline 7802 & 14,18 & 24.66 & 25.78 & 30.79 \\
\hline 7003 & $8,13,14$ & 29.26 & 29.46 & 37.80 \\
\hline 7016 & $8,13,14$ & 22.44 & 13.61 & 22.74 \\
\hline Total & & 132.26 & 132.55 & 167.59 \\
\hline
\end{tabular}

Table 2: Required switch items [MSU].

\begin{tabular}{|c|c|c|c|c|}
\hline \multirow{2}{*}{} & \multicolumn{4}{|c|}{ Machines } \\
\cline { 2 - 5 } & 8 & 13 & 14 & 18 \\
\hline 4341 & 11.33 & 9.72 & & \\
\hline 7001 & 7.52 & 6.56 & & \\
\hline 7018 & & & 9.04 & 9.92 \\
\hline 7802 & & & 7.44 & 7.89 \\
\hline 7003 & 7.52 & 6.56 & 5.92 & \\
\hline 7016 & 10.62 & 8.96 & & 9.68 \\
\hline
\end{tabular}

Table 3: Productivity of switch item machines [hours/MSU].

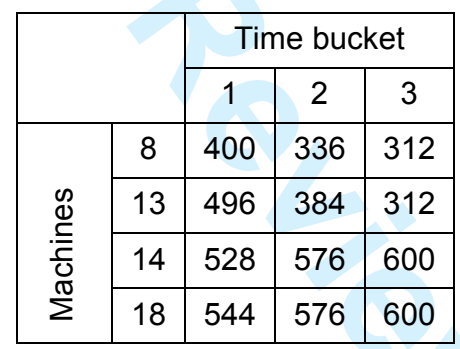

Table 4: Available capacity for item manufacturing [hours].

\begin{tabular}{|c|c|c|c|c|}
\hline & \multicolumn{3}{|c|}{ Time bucket } \\
\hline & & 1 & 2 & 3 \\
\hline \multirow{4}{*}{ 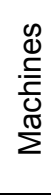 } & 8 & 0.08 & 0.21 & 0.25 \\
\hline & 13 & 0.14 & 0.27 & 0.35 \\
\hline & 14 & 0.49 & 0.50 & 0.55 \\
\hline & 18 & 0.30 & 0.35 & 0.48 \\
\hline
\end{tabular}

Table 5: Saturation coefficients of switch item machines. 


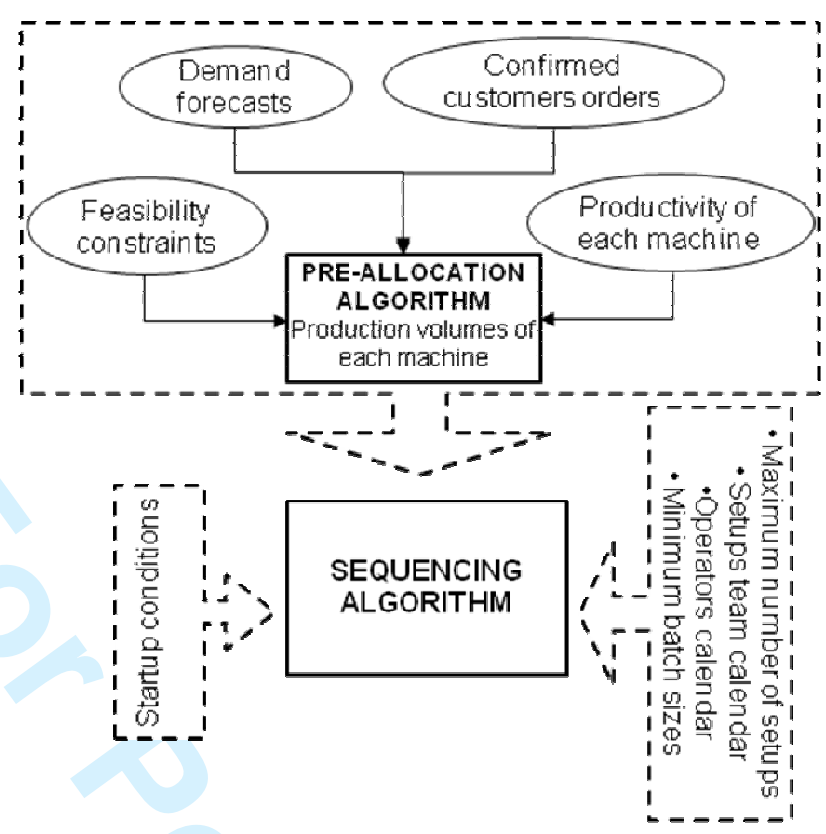

Figure 1: Framework of the solution approach.

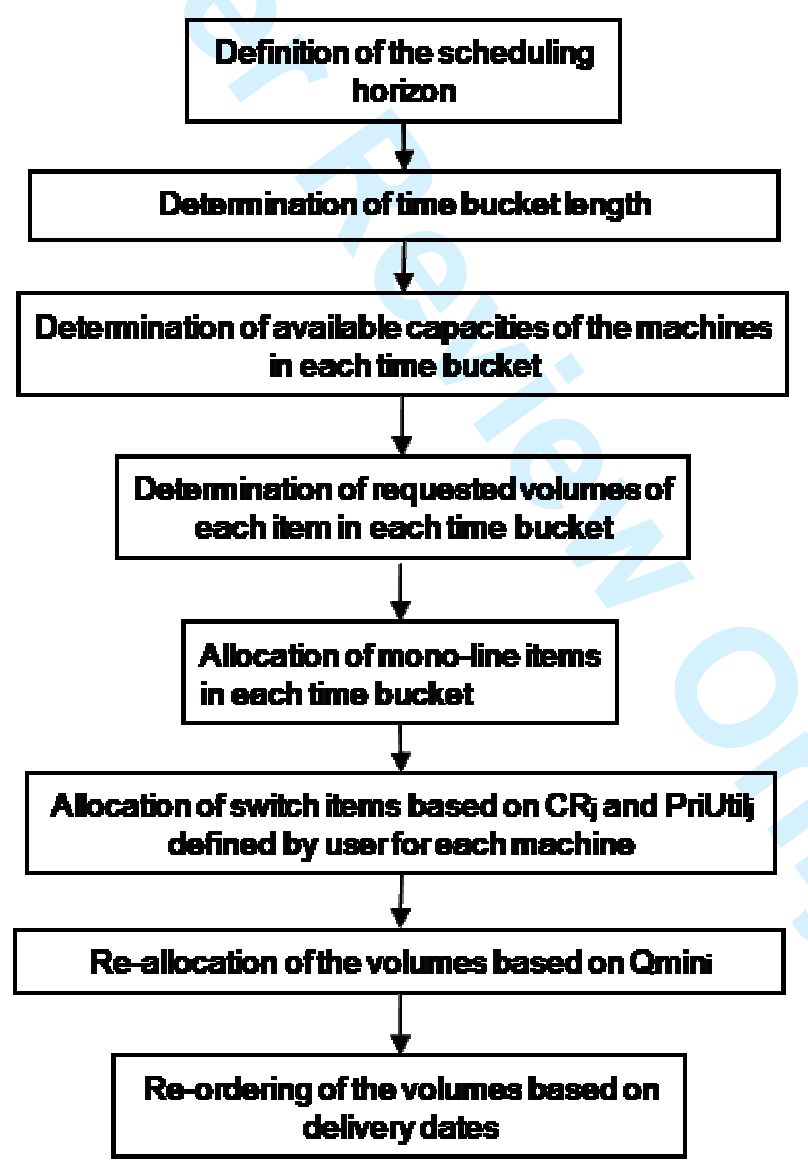

Figure 2: Framework of $\mathrm{H} 1$. 
1

Figure 3: Framework of $\mathrm{H} 2$. 
1

2

3

4

5

6

7

8

9

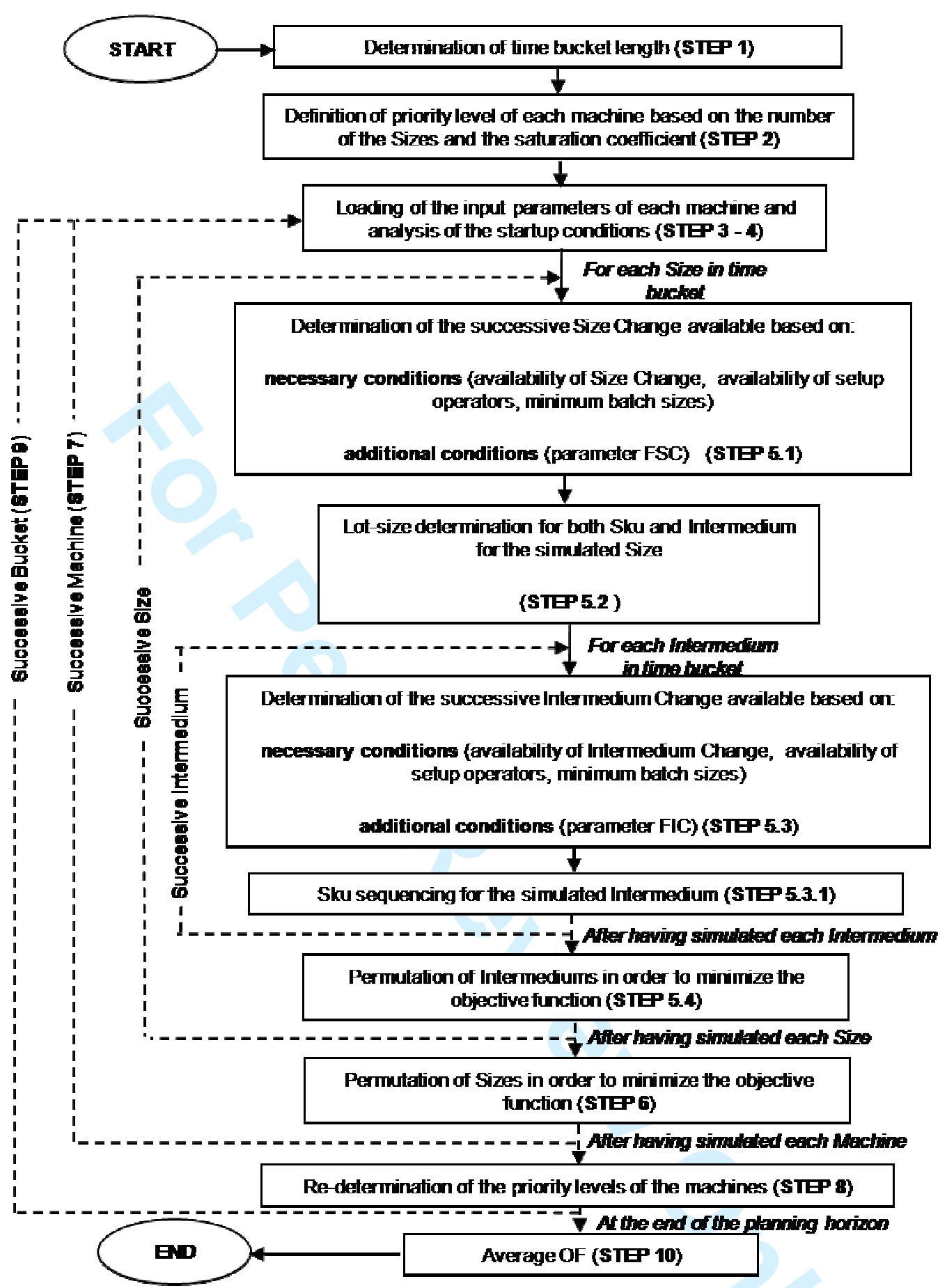

Figure 4: Sequencing algorithm scheme.

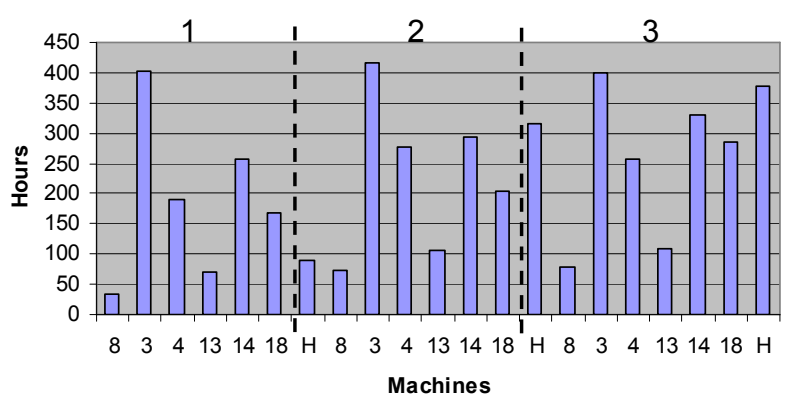

Figure 5: Required capacity for allocation of mono-line items. 


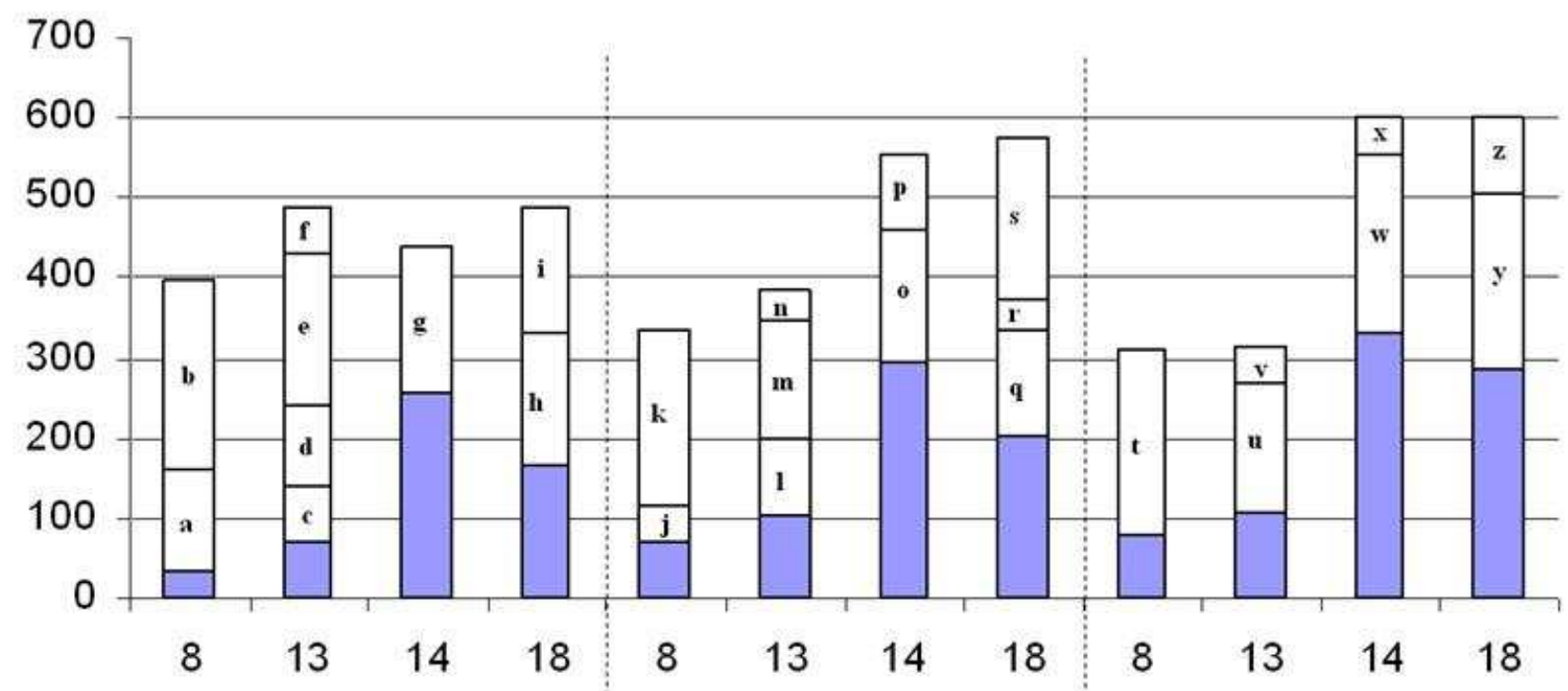

Figure 6: Volume pre-allocations achieved by the mathematical model in solution S1.

\begin{tabular}{|c|c|c|c|c|}
\hline Id & Item & $\begin{array}{l}\text { Planned time } \\
\text { bucket }\end{array}$ & $\begin{array}{l}\text { Early switch } \\
\text { item }\end{array}$ & $\begin{array}{c}\text { Unsatisfied switch } \\
\text { item }\end{array}$ \\
\hline a & 7001 & 1 & $\mathrm{~N}$ & $\mathrm{~N}$ \\
\hline b & 7016 & 1 & $\mathrm{~N}$ & $\mathrm{~N}$ \\
\hline c & 4341 & 1 & $\mathrm{~N}$ & $\mathrm{~N}$ \\
\hline d & 7001 & $\mathrm{~V}$ & $\mathrm{~N}$ & $\mathrm{~N}$ \\
\hline $\mathrm{e}$ & 7003 & 1 & 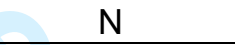 & $\mathrm{N}$ \\
\hline $\mathrm{f}$ & 4341 & 2 & (e) & $\mathrm{N}$ \\
\hline g & 7802 & 1 & $\mathrm{~N}$ & $\mathrm{~N}$ \\
\hline $\mathrm{h}$ & 7018 & 1 & 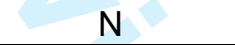 & $\mathrm{N}$ \\
\hline $\mathrm{i}$ & 7018 & 2 & $Y$ & $\mathrm{~N}$ \\
\hline j & 7001 & 2 & $\mathrm{~N}$ & $\mathrm{~N}$ \\
\hline $\mathrm{k}$ & 7003 & 2 & 2 & $\mathrm{~N}$ \\
\hline 1 & 4341 & 2 & 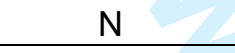 & $\mathrm{N}$ \\
\hline $\mathrm{m}$ & 7001 & 2 & $\mathrm{~N}$ & $\mathrm{~N}$ \\
\hline $\mathrm{n}$ & 4341 & 3 & $\mathrm{Y}$ & 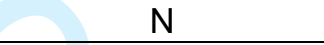 \\
\hline 0 & 7018 & 3 & $Y$ & 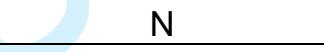 \\
\hline $\mathrm{p}$ & 7802 & 3 & Y & 2 \\
\hline$q$ & 7016 & 2 & $\mathrm{~N}$ & $V$ \\
\hline$r$ & 7018 & 2 & $\mathrm{~N}$ & 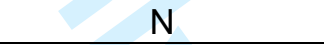 \\
\hline $\mathrm{s}$ & 7802 & 2 & $\mathrm{~N}$ & $\mathrm{~N}$ \\
\hline $\mathrm{t}$ & 7001 & 3 & $\mathrm{~N}$ & $\mathrm{~N}$ \\
\hline $\mathrm{u}$ & 4341 & 3 & $\mathrm{~N}$ & $\mathrm{~N}$ \\
\hline $\mathrm{v}$ & 7001 & 3 & $\mathrm{~N}$ & $\mathrm{~N}$ \\
\hline w & 7003 & 3 & $\mathrm{~N}$ & $\mathrm{~N}$ \\
\hline$x$ & 7802 & 3 & $\mathrm{~N}$ & $\mathrm{~N}$ \\
\hline $\mathrm{y}$ & 7016 & 3 & $\mathrm{~N}$ & $\mathrm{~N}$ \\
\hline $\mathrm{z}$ & 7802 & 3 & $\mathrm{~N}$ & $\mathrm{~N}$ \\
\hline
\end{tabular}

Table 6: Volume pre-allocations achieved by the mathematical model in solution S1. 


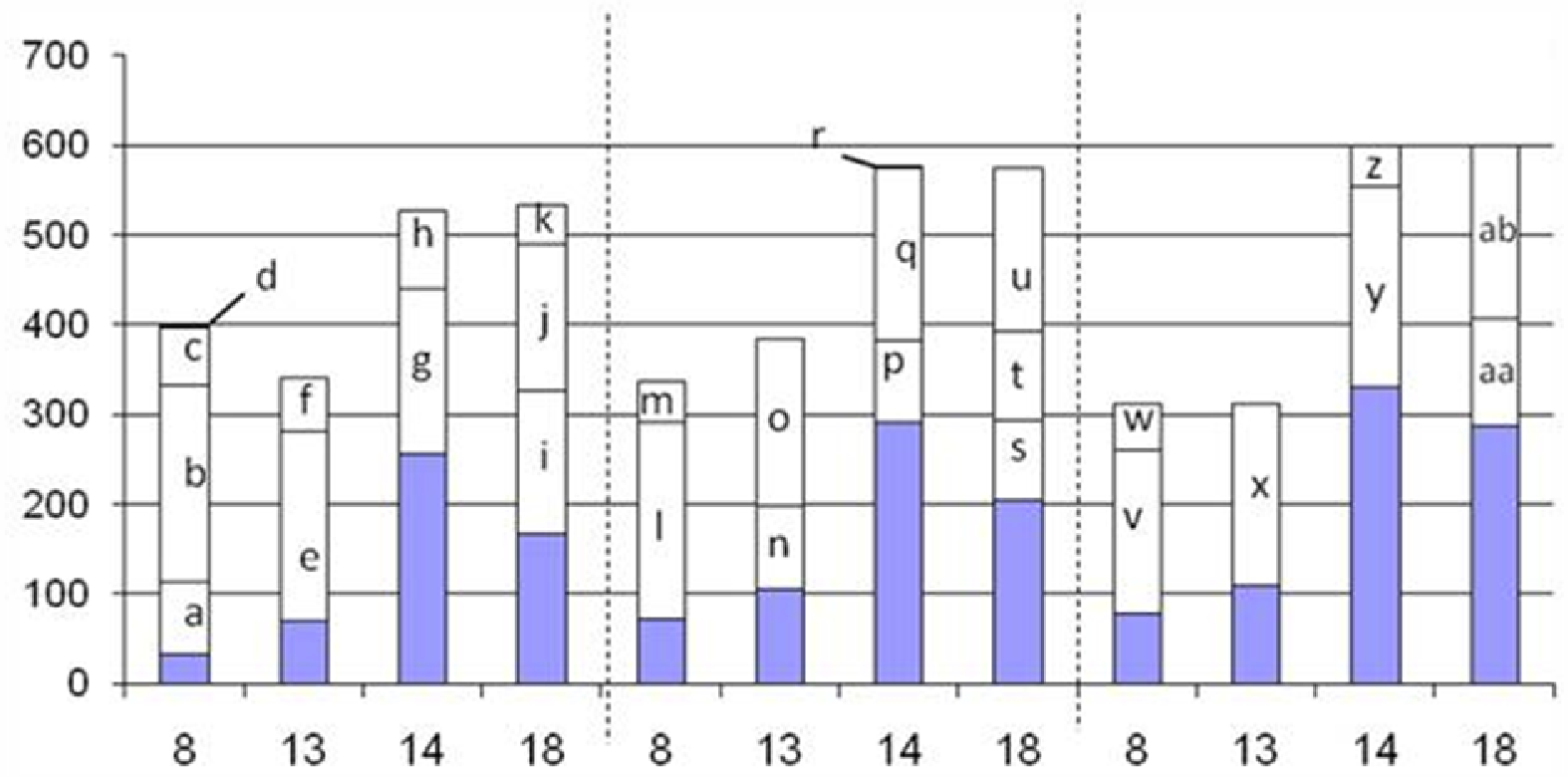

Figure 7: Volume pre-allocations achieved by the mathematical model in solution S2.

\begin{tabular}{|c|c|c|c|c|}
\hline Id & Item & $\begin{array}{c}\text { Planned time } \\
\text { bucket }\end{array}$ & $\begin{array}{l}\text { Early switch } \\
\text { item }\end{array}$ & $\begin{array}{c}\text { Unsatisfied switch } \\
\text { item }\end{array}$ \\
\hline a & 4341 & 1 & $\mathrm{~N}$ & $\mathrm{~N}$ \\
\hline b & 7003 & 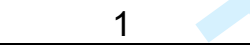 & $\mathrm{N}$ & $\mathrm{N}$ \\
\hline c & 7016 & 1 & $\mathrm{~N}$ & $\mathrm{~N}$ \\
\hline$d$ & 7003 & 2 & 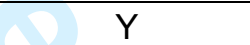 & $\mathrm{N}$ \\
\hline e & 7001 & 1 & av & $\mathrm{N}$ \\
\hline f & 4341 & 2 & Y & $\mathrm{N}$ \\
\hline$g$ & 7802 & 1 & $\mathrm{~N}$ & $\mathrm{~N}$ \\
\hline $\mathrm{h}$ & 7018 & 2 & $Y$ & $\mathrm{~N}$ \\
\hline $\mathrm{i}$ & 7016 & 1 & $\mathrm{~N}$ & $\mathrm{~N}$ \\
\hline$j$ & 7018 & 1 & $\mathrm{~N}$ & $\mathrm{~N}$ \\
\hline$k$ & 7016 & 2 & $\mathrm{Y}$ & $\mathrm{N}$ \\
\hline 1 & 7003 & 2 & $\mathrm{~N}$ & 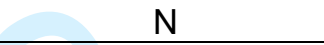 \\
\hline$m$ & 4341 & 3 & $\mathrm{Y}$ & $\mathrm{N}$ \\
\hline $\mathrm{n}$ & 4341 & 2 & $\mathrm{~N}$ & 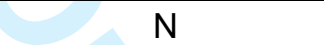 \\
\hline 0 & 7001 & 2 & $\mathrm{~N}$ & 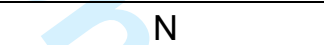 \\
\hline$p$ & 7018 & 2 & $\mathrm{~N}$ & $N$ \\
\hline$q$ & 7802 & 2 & $\mathrm{~N}$ & $\mathrm{~N}$ \\
\hline$r$ & 7802 & 3 & $\mathrm{Y}$ & $\bar{C}$ \\
\hline $\mathrm{s}$ & 7016 & 2 & $\mathrm{~N}$ & $\mathrm{~N}$ \\
\hline$t$ & 7016 & 3 & $\mathrm{Y}$ & $\mathrm{N}$ \\
\hline $\mathrm{u}$ & 7018 & 3 & $Y$ & $\mathrm{~N}$ \\
\hline $\mathrm{v}$ & 4341 & 3 & $\mathrm{~N}$ & $\mathrm{~N}$ \\
\hline$w$ & 7001 & 3 & $\mathrm{~N}$ & $\mathrm{~N}$ \\
\hline$x$ & 7001 & 3 & $\mathrm{~N}$ & $\mathrm{~N}$ \\
\hline$y$ & 7003 & 3 & $\mathrm{~N}$ & $\mathrm{~N}$ \\
\hline$z$ & 7802 & 3 & $\mathrm{~N}$ & $\mathrm{~N}$ \\
\hline aa & 7016 & 3 & $\mathrm{~N}$ & $\mathrm{~N}$ \\
\hline$a b$ & 7802 & 3 & $\mathrm{~N}$ & $\mathrm{~N}$ \\
\hline
\end{tabular}

Table 7: Volume pre-allocations achieved by the mathematical model in solution S2. 


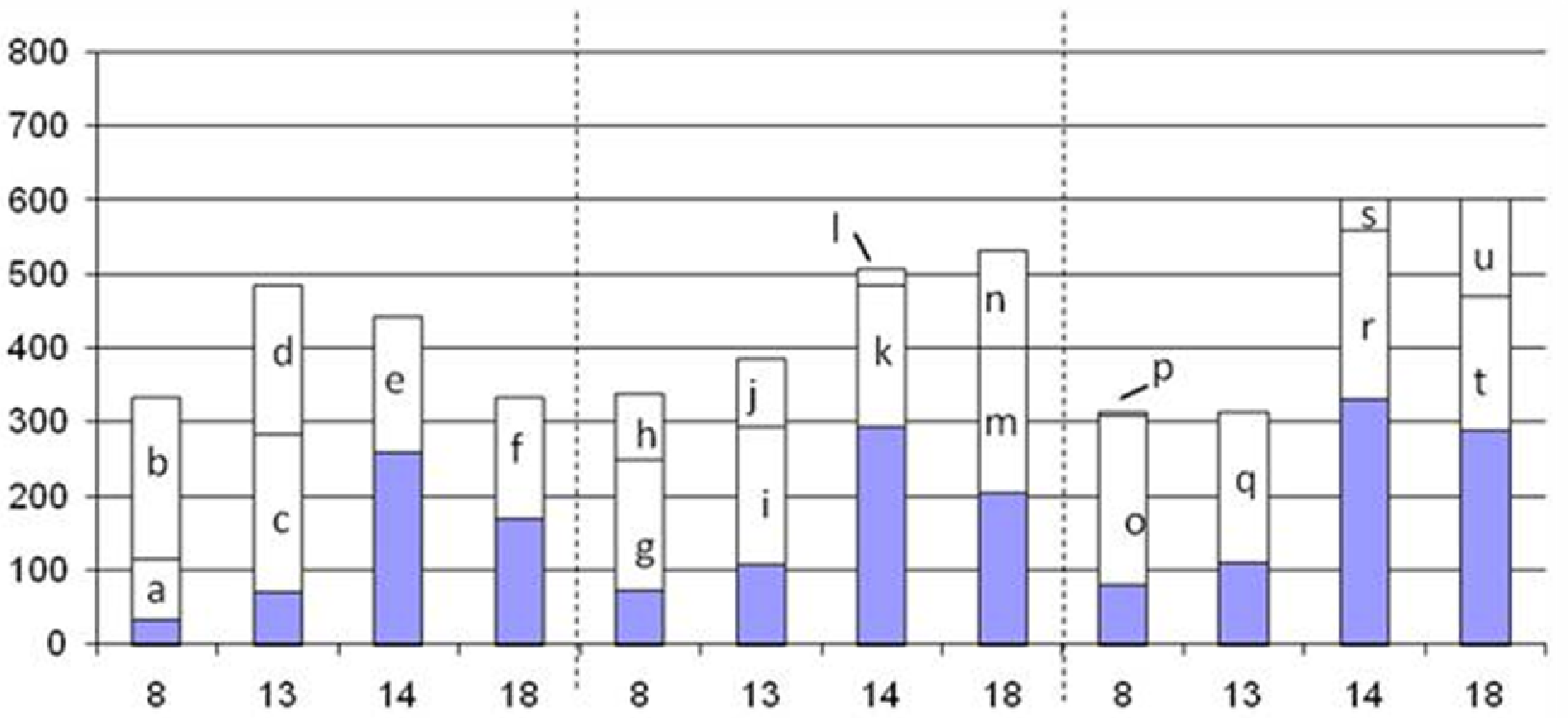

Figure 8: Volume pre-allocations achieved by the heuristic $\mathrm{H} 1$.

\begin{tabular}{|c|c|c|c|c|}
\hline Id & Item & $\begin{array}{c}\text { Planned time } \\
\text { bucket }\end{array}$ & $\begin{array}{l}\text { Early switch } \\
\text { items }\end{array}$ & $\begin{array}{l}\text { Unsatisfied switch } \\
\text { items }\end{array}$ \\
\hline$a$ & 4341 & 1 & $\mathrm{~N}$ & $\mathrm{~N}$ \\
\hline b & 7003 & 1 & $\mathrm{~N}$ & $\mathrm{~N}$ \\
\hline c & 7001 & 1 & $\mathrm{~N}$ & $\mathrm{~N}$ \\
\hline $\mathrm{d}$ & 7016 & 1 & $\mathrm{~N}$ & $\mathrm{~N}$ \\
\hline $\mathrm{e}$ & 7802 & 1 & $\mathrm{~N}$ & $\mathrm{~N}$ \\
\hline $\mathrm{f}$ & 7018 & 1 & $\mathrm{~N}$ & $\mathrm{~N}$ \\
\hline $\mathrm{g}$ & 4341 & 2 & $\mathrm{~N}$ & $\mathrm{~N}$ \\
\hline $\mathrm{h}$ & 7003 & 2 & $\mathrm{~N}$ & $\mathrm{~N}$ \\
\hline $\mathrm{i}$ & 7001 & 2 & $\mathrm{~N}$ & $\mathrm{~N}$ \\
\hline j & 7003 & 2 & $\mathrm{~N}$ & $\mathrm{~N}$ \\
\hline $\mathrm{k}$ & 7802 & 2 & $\mathrm{~N}$ & $\mathrm{~N}$ \\
\hline 1 & 7003 & 2 & $\mathrm{~N}$ & $\mathrm{~N}$ \\
\hline $\mathrm{m}$ & 7018 & 2 & $\mathrm{~N}$ & $\mathrm{~N}$ \\
\hline $\mathrm{n}$ & 7016 & 2 & $\mathrm{~N}$ & $\mathrm{~N}$ \\
\hline 0 & 4341 & 3 & $\mathrm{~N}$ & 2 \\
\hline $\mathrm{p}$ & 7001 & 3 & $\mathrm{~N}$ & $\mathrm{~N}$ \\
\hline$q$ & 7001 & 3 & $\mathrm{~N}$ & $\mathrm{~N}$ \\
\hline $\mathrm{r}$ & 7802 & 3 & $\mathrm{~N}$ & $\mathrm{~N}$ \\
\hline $\mathrm{s}$ & 7003 & 3 & $\mathrm{~N}$ & $\mathrm{~N}$ \\
\hline $\mathrm{t}$ & 7018 & 3 & $\mathrm{~N}$ & $\mathrm{~N}$ \\
\hline \multirow[t]{4}{*}{$\mathrm{u}$} & 7016 & 3 & $\mathrm{~N}$ & $\mathrm{~N}$ \\
\hline & 7001 & 3 & $\mathrm{~N}$ & $Y$ \\
\hline & 7003 & 3 & $\mathrm{~N}$ & $\mathrm{Y}$ \\
\hline & 7016 & 3 & $\mathrm{~N}$ & $\mathrm{Y}$ \\
\hline
\end{tabular}

Table 8: Volume pre-allocations achieved by the heuristic $\mathrm{H} 1$. 


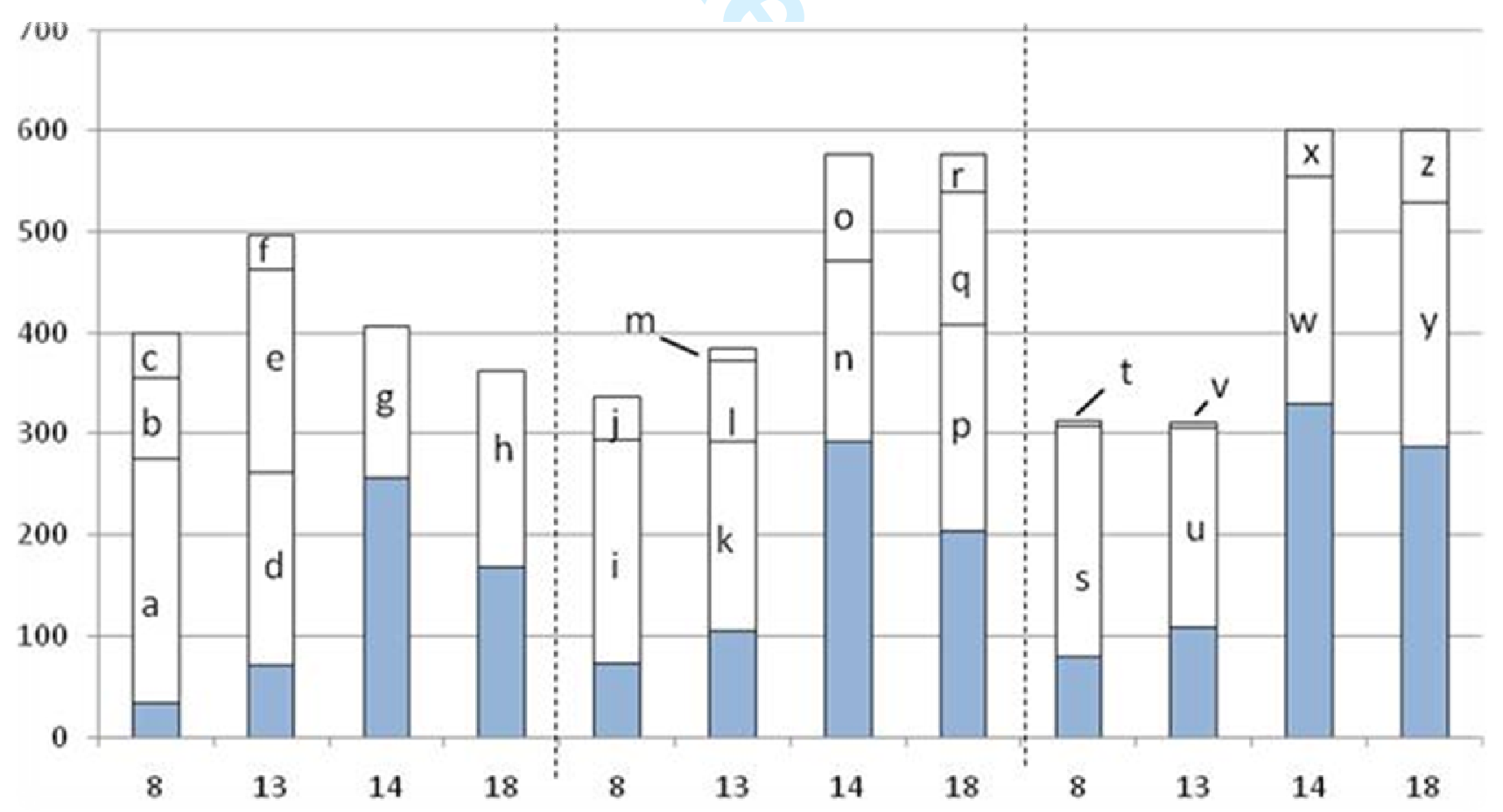

Figure 9: Volume pre-allocations achieved by the heuristic $\mathrm{H} 2$. 


\begin{tabular}{|c|c|c|c|c|}
\hline Id & Item & $\begin{array}{c}\text { Planned time } \\
\text { bucket }\end{array}$ & $\begin{array}{l}\text { Early switch } \\
\text { item }\end{array}$ & $\begin{array}{c}\text { Unsatisfied switch } \\
\text { item }\end{array}$ \\
\hline a & 7001 & 1 & $\mathrm{~N}$ & $\mathrm{~N}$ \\
\hline$b$ & 4341 & 1 & $\mathrm{~N}$ & $\mathrm{~N}$ \\
\hline c & 4341 & 2 & $\mathrm{Y}$ & $\mathrm{N}$ \\
\hline$d$ & 7003 & 1 & $\mathrm{~N}$ & $\mathrm{~N}$ \\
\hline $\mathrm{e}$ & 7016 & 1 & $\mathrm{~N}$ & $\mathrm{~N}$ \\
\hline$f$ & 4341 & 2 & $\mathrm{Y}$ & $\mathrm{N}$ \\
\hline $\mathrm{g}$ & 7018 & 1 & $\mathrm{~N}$ & $\mathrm{~N}$ \\
\hline $\mathrm{h}$ & 7802 & 1 & $\mathrm{~N}$ & $\mathrm{~N}$ \\
\hline$i$ & 7003 & 2 & $\mathrm{~N}$ & $\mathrm{~N}$ \\
\hline $\mathrm{j}$ & 7001 & 3 & $Y$ & $\mathrm{~N}$ \\
\hline $\mathrm{k}$ & 7001 & 2 & $\mathrm{~N}$ & $\mathrm{~N}$ \\
\hline 1 & 4341 & 2 & $\mathrm{~N}$ & $\mathrm{~N}$ \\
\hline $\mathrm{m}$ & 7001 & 3 & $Y$ & $\mathrm{~N}$ \\
\hline $\mathrm{n}$ & 7018 & 2 & $\mathrm{~N}$ & $\mathrm{~N}$ \\
\hline 0 & 7018 & 3 & $Y$ & $\mathrm{~N}$ \\
\hline$p$ & 7802 & 2 & $\mathrm{~N}$ & $\mathrm{~N}$ \\
\hline$q$ & 7016 & 2 & $\mathrm{~N}$ & $\mathrm{~N}$ \\
\hline$r$ & 7016 & 3 & $Y$ & $\mathrm{~N}$ \\
\hline $\mathrm{s}$ & 4341 & 3 & $\mathrm{~N}$ & $\mathrm{~N}$ \\
\hline$t$ & 7016 & 3 & $\mathrm{~N}$ & $\mathrm{~N}$ \\
\hline $\mathrm{u}$ & 7001 & 2 & $\mathrm{~N}$ & $\mathrm{~N}$ \\
\hline $\mathrm{v}$ & 7016 & 3 & $\mathrm{~N}$ & $\mathrm{~N}$ \\
\hline$w$ & 7003 & 3 & $\mathrm{~N}$ & $\mathrm{~N}$ \\
\hline$x$ & 7018 & 3 & 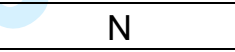 & $\mathrm{N}$ \\
\hline$y$ & 7802 & 3 & 2 & $\mathrm{~N}$ \\
\hline \multirow[t]{3}{*}{$z$} & 7016 & 3 & 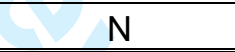 & $\mathrm{N}$ \\
\hline & 7016 & 3 & $\mathrm{~N}$ & $\bar{Y}$ \\
\hline & 7018 & 3 & $\mathrm{~N}$ & $\bar{Y}$ \\
\hline
\end{tabular}

Table 11: Volume pre-allocations achieved by the heuristic $\mathrm{H} 2$.

\begin{tabular}{|l|c|c|c|c|}
\hline & $\begin{array}{c}\text { Mathematical } \\
\text { Model - S1 }\end{array}$ & $\begin{array}{c}\text { Mathematical } \\
\text { Model - S2 }\end{array}$ & $\mathrm{H} 1$ & $\mathrm{H} 2$ \\
\hline $\begin{array}{l}\text { Average number of split } \\
\text { volumes }\end{array}$ & 1.3 & 1.2 & 1.2 & 1.3 \\
\hline $\begin{array}{l}\text { Average unsatisfied } \\
\text { switch demand }\end{array}$ & $0.0 \%$ & $0.0 \%$ & $9.2 \%$ & $2.4 \%$ \\
\hline $\begin{array}{l}\text { Average early switch } \\
\text { demand }\end{array}$ & $10.0 \%$ & $10.2 \%$ & $0.0 \%$ & $12.2 \%$ \\
\hline $\begin{array}{l}\text { Average switch filling } \\
\text { rate }\end{array}$ & $95.3 \%$ & $96.7 \%$ & $92.1 \%$ & $95.3 \%$ \\
\hline
\end{tabular}

Table 12: Experimental results. 


\section{References}

Akkiraju, R., Keskinocak, P., Murthy, S. and Wu, F., 2001. An agent-based approach for scheduling multiple machines. Applied Intelligence, 14, 135-144.

Allahverdi, A., Gupta, J.N.D. and Aldowaisan, T., 1999. A review of scheduling research involving setup considerations. The International Journal of Management Science, 27, 219-239.

Allahverdi, A., Ng, C.T., Cheng, T.C.E. and Kovalyov, M.Y., 2008. A survey of scheduling problems with setup times or costs. European Journal of Operational Research, 187, 985-1032.

Arnaout, J.-P., Rabadi, G. and Mun, J.H., 2006. A dynamic heuristic for the stochastic unrelated parallel machine scheduling problem. International Journal of Operations Research, 3, 136-143.

Berning, G., Brandenburg, M., Gürsoy, K., Mehta, V. and Tölle F.-J., 2002. An integrated system solution for supply chain optimization in the chemical process industry. OR Spectrum, 24, 371-401.

Celano, G., Costa, A. and Fichera, S., 2008. Scheduling of unrelated parallel manufacturing cells with limited human resources. International Journal of Production Research, 46, 405-427.

Chang, P.-T., Lin, K.-P., Pai, P.-F., Zhong, C.-Z., Lin, C.-H. and Hung, L.-T., 2008. Ant colony optimization system for a multi-quantitative and qualitative objective job-shop parallel-machine-scheduling problem. International Journal of Production Research, 46, 5719-5759.

Cheng, T.C.E., Gupta, J.N.D. and Wang, G., 2000. A review of flowshop scheduling research setup times. Production and Operations Management, 9, 262-282.

Chuang, M.-C., Liao, C.-J. and Chao, C.-W, 2009. Parallel machine scheduling with preference of machines. International Journal of Production Research, doi 10.1080/00207540902991674

Clark, A.R. and Clark, S.J., 2000. Rolling-horizon lot-sizing when setup times are sequence-dependent. International Journal of Production Research, 38, 2287-2307.

Drexl, A. and Kimms, A., 1997. Lot sizing and scheduling-Survey and extensions. European Journal of Operational Research, 99, $221-235$.

Fandel, G. and Stammen-Hegene, C., 2006. Simultaneous lot sizing and scheduling for multi-product multi-level production. International Journal of Production Economics, 104, 308-316.

Gamberini, R., Grassi, A., Mora, C., and Rimini, B., 2005. A framework for addressing job shop scheduling in a real industrial context. $7^{\text {th }}$ International Conference on the "Modern Information Technology in the Innovation Processes of the industrial enterprises" (MITIP), $8^{\text {th }}-9^{\text {th }}$ September, Genova, Italy.

$\mathrm{Hu}, \mathrm{X}$., Bao, J.-S. and Jin, Y., 2010. Minimising makespan on parallel machines with precedence constraints and machine eligibility restrictions. International Journal of Production Research, 48, 1639-1651.

Jeong, B., Kim, S.-W. and Lee, Y.J., 2001. An assembly scheduler for TFT LCD manufacturing. Computers \& Industrial Engineering, 41, 3758.

Kang, S., Malik, K. and Thomas, L.J., 1999. Lotsizing and scheduling on parallel machines with sequence-dependent setup costs. Management Science, 45, 273-289.

Karimi, B., Fatemi Ghomi, S.M.T. and Wilson, J.M., 2003. The capacitated lot sizing problem: A review of models and algorithms. Omega, 31, 365-378

Kim, D.-W., Kim, K.-H., Jang, W. and Chen, F.F., 2002. Unrelated parallel machine scheduling wit setup times using simulated annealing. Robotics and Computer-Integrated Manufacturing, 18, 223-231.

Kim, D.-W., Na, D.-G. and Chen, F.F., 2003. Unrelated parallel machines scheduling with setup times and a total weighted tardiness objective. Robotics and Computer-Integrated Manufacturing, 19, 173-181.

Kim, D.-W., Na, D.-G., Jang, W. and Chen, F.F., 2006. Simulated annealing and genetic algorithm for unrelated parallel machine scheduling considering setup times. International Journal of Computer Applications in Technology, 1/2, 28-36.

Liaee, M.M. and Emmons, H., 1997. Scheduling families of jobs with setup times. International Journal of Production Economics, 51, 165176.

Meyr, H., 2002. Simultaneous lotsizing and scheduling on parallel machines. European Journal of Operational Research, 139, $277-292$.

Monkman, S.K., Morrice, D.J. and Bard, J.F., 2008. A production scheduling heuristic for an electronics manufacturer with sequencedependent setup costs. European Journal of Operational Research, 187, 1100-1114.

Pinto J.M., Grossmann I.E., 1998. Assignment and sequencing models for the scheduling of process systems. Annals of Operations Research, 81, 433-466.

Potts, C.N. and Kovalyov, M.Y., 2000. Scheduling with batching: a review. European Journal of Operational Research, 120, $228-249$.

Salomon, M., Kroon, L.G., Kuik, R. and Van Wassenhove, L.N., 1991. Some extensions of the discrete lot sizing and scheduling problem. Management Science, 801-812.

Yang, W.H. and Liao, C.J., 1998. Batching and sequencing of jobs with order availability at a single facility. International Journal of Systems Science, 29, 13-20. 